\title{
Measuring brand awareness as a component of eating habits in children: The development of the IBAI questionnaire in Georgia
}

\author{
Maria Gabriella Vecchio ${ }^{\mathrm{a}}$, Irakli L. Rtskhladze ${ }^{\mathrm{b}}$, Giulia Lorenzonic ${ }^{\mathrm{c}}$, Lela Zangurashvilib, \\ Nino Kankia ${ }^{\mathrm{b}}$, Maka Lomidze ${ }^{\mathrm{b}}$, Zakalashvili T. Andriadze ${ }^{\mathrm{b}}$, Danila Azzolina ${ }^{\mathrm{c}}$ and Dario Gregori ${ }^{\mathrm{c}, *}$ \\ ${ }^{\mathrm{a}}$ Zeta Research Ltd, Trieste, Italy \\ ${ }^{\mathrm{b}}$ Medical Centre Mrcheveli, Tbilisi, Georgia \\ ${ }^{\mathrm{c}}$ Unit of Biostatistics, Epidemiology and Public Health, Department of Cardiac, Thoracic and Vascular Sciences, \\ University of Padova, Italy
}

Received 2 May 2017

Accepted 16 June 2017

\begin{abstract}
.
BACKGROUND: Environmental factors play a key role in obesity development. In recent years, it has been advocated particularly the role of food advertising in promoting the consumption of energy-dense food.

OBJECTIVE: The aim of the present work is to develop an instrument to estimate Georgian children's brand awareness.

METHODS: We developed the IBAI (International Brand Awareness Instrument), an age-appropriate instrument that consists of twelve sheets with pictures of food logos to test children's recall and recognition of brands. The IBAI was presented to a sample of 120 children aged 3-11 years, enrolled in the city of Tbilisi (Georgia).

RESULTS: Referring to the total score of each child, $46.7 \%$ of children showed a very-low brand awareness, followed by medium-low brand awareness (28.3\%), medium-high brand awareness (19.2\%) and very high brand awareness (5.8\%).

CONCLUSIONS: Even though most of the Georgian children enrolled showed a very-low brand awareness, considering that children's scores for the IBAI ranged in all the four identified categories, we can assume that this instrument allow distinguishing different kinds of children's brand awareness.
\end{abstract}

Keywords: Brand awareness, children, Georgia, IBAI

\section{Introduction}

Nowadays, obesity epidemic represents a severe public health burden both in developed and newly industrialized countries [1], involving both children and adults [2]. Several factors have been described to be associated with obesity onset, and the most relevant are represented by biological ones. Genetic seems to play a key role in affecting obesity onset, by influencing mechanisms underlying energy balance [3]. However, it is well-known that also environmental factors are crucial predictors of obesity: the adoption of sedentary behaviors, together

\footnotetext{
${ }^{*}$ Corresponding author: Dario Gregori, Unit of Biostatistics, Epidemiology and Public Health, Department of Cardiac, Thoracic and Vascular Sciences, University of Padova, Via Loredan 18, 35131 Padova, Italy. Tel.: +39 049 8275384; Fax: +39 02 700445089; E-mail: dario.gregori@unipd.it.
} 
with the consumption of energy-dense food, may result in weight gain. One of the most important environmental risk factors for childhood obesity is represented by TV viewing [4, 5], which results in a reduction of time spent doing physical activity and it is often accompanied by food consumption [6], mainly of calorically-dense food items (sweet and salty snacks) [7, 8].

The role played by TV viewing and food advertising in promoting childhood obesity has been widely debated by international scientific literature. It has been shown to be associated with dietary patterns, body weight, and health status in short [8-11] and in long term [12]. More specifically, food advertisement seems to promote the consumption of marketed food by stimulating hunger [13].

Food advertising is aimed at promoting brand recognition by encouraging children's emotional attachment to the brand (and, consequently, long-term brand loyalty) [14]. Several studies suggest that food marketing alters children's preference for specific food brands $[13,15,16]$, raising the hypothesis that it acts as a cue for food consumption. However, only a few tools are available for assessing brand awareness in schoolchildren, which represent the age class to which are aimed most of food advertisements. The first instrument was developed for U.S. children by Forman and coworkers. In brief, it consists in a logo-matching exercise made of 30 pictures representative of food brand logos. Obviously, since some food brand logos are very common worldwide (i.e., McDonald's ${ }^{\odot}$ ) while others are country-specific, this brand awareness instrument has been developed primarily for U.S. children [17].

A significant lack of country- or cultural-specific instruments is noticeable, making the assessment of children brand awareness difficult to be standardized.

Considering the lack of tools useful for the evaluation of children brand awareness, the main aim of the present study was the development of an instrument (IBAI (International Brand Awareness Instrument)) to assess brand recognition and recall of Georgian children.

\section{Material and methods}

\subsection{Stimuli selection}

In line with the study of Forman et al. [17], we developed the IBAI paying attention in particular to the food brand selection. Three product categories were selected as stimuli: sweet snack, salted snack, and soft drinks. These foods were selected based on discussions between the investigators working on this project (between psychologists and pedagogues). We used two criteria in selecting the brands. First, the brands had to be available in most of the Georgian supermarkets. Second, the brands must represent food products aimed to children.

In Table 1, the complete list of brands selected is presented.

\subsection{Instrument development}

Each of the brand selected was paired with 4 pictures of foods, so that only one of such food products' images could be properly matched with the logo.

Twelve sheets, called flash cards, with one logo and four pictures of food products were created. An example of such flash cards is reported in Fig. 1.

All pictures, a total of 12 brand logos, and 48 food products ( 4 per brand), were laminated in $8 \times 11.5$ sheets and placed in a 3-ring binder for ease of presentation to the children [17].

\subsection{Study sample}

A total of 120 children, 60 girls and 60 boys, aged 3-11 years, were enrolled in the study for the development of the IBAI. They were enrolled in a school of Tbilisi in February 2012. Children were enrolled to be balanced by gender and age group. 
Table 1

Complete list of brands used for the development of the International Brand Awareness Instrument (IBAI) -Georgia

\begin{tabular}{|c|c|c|c|c|c|c|}
\hline \multicolumn{2}{|c|}{ Flash Card Brand } & \multirow{2}{*}{$\frac{\text { Solution }}{\mathrm{A}}$} & \multirow{2}{*}{$\begin{array}{l}\text { Product } 1 \\
\text { Coca Cola }\end{array}$} & \multirow{2}{*}{$\begin{array}{l}\text { Product } 2 \\
\text { milk }\end{array}$} & \multirow{2}{*}{$\begin{array}{l}\text { Product } 3 \\
\text { orange }\end{array}$} & \multirow{2}{*}{$\begin{array}{l}\text { Product } 4 \\
\text { chocolate }\end{array}$} \\
\hline 1 & $\begin{array}{l}\text { Coca Cola }{ }^{\circledR} \\
\text { Koka-Kola }^{\circledR}\end{array}$ & & & & & \\
\hline 2 & $\begin{array}{l}\text { Mc Donald }{ }^{\circledR} \\
\text { Makdonaldsi }^{\circledR}\end{array}$ & $\mathrm{C}$ & pasta & toast & hamburger & fish \\
\hline 3 & $\begin{array}{l}\text { Bami King } \\
{ }^{\odot} \\
\text { Bami King }\end{array}$ & $\mathrm{D}$ & wafer & filled biscuits & biscuits & brioches \\
\hline 4 & $\begin{array}{l}\text { Pringles }{ }^{\circledR} \\
\text { Pringlsi }{ }^{\circledR}\end{array}$ & A & Pringles potatoes & potato chips & peanuts & gummy candies \\
\hline 5 & $\begin{array}{l}\text { Algida }^{\circledR} \\
\text { Algida }^{\circledR}\end{array}$ & $\mathrm{C}$ & creme caramel & yogurt & Cuore di panna & gummy candies \\
\hline 6 & $\begin{array}{l}\text { Milka } \\
\text { Milka }\end{array}$ & A & chocolate bar & creme caramel & chocolate pudding & ice cream \\
\hline 7 & $\begin{array}{l}\text { Kinder }^{\circledR} \\
\text { Qinderi }^{\circledR}\end{array}$ & $\mathrm{C}$ & chocolate bar & chocolate brioche & Délice & chocolate pudding \\
\hline 8 & $\begin{array}{l}\text { Nestlè }^{\circledR} \\
\text { Nestle }^{\circledR}\end{array}$ & A & kit kat & biscuits & cornflakes & gummy candies \\
\hline 9 & $\begin{array}{l}\text { Danone } \\
\text { Danoni }\end{array}$ & A & pudding (Danette) & ice cream & chocolate bar & smarties \\
\hline 10 & $\begin{array}{l}\text { Nesquik }^{\circledR} \\
\text { Nesqviki }^{\circledR}\end{array}$ & A & chocolate-milk & milk & orange-juice & cola \\
\hline 11 & $\begin{array}{l}\text { Chupa-chups }{ }^{\circledR} \\
\text { Cupa-Cupsi }^{\circledR}\end{array}$ & A & lollipop & fruit drop & gummy candy & sugared almond \\
\hline 12 & $\begin{array}{l}3 \text { Koronchki }^{\circledR} \\
3 \text { KoroCki }^{\circledR}\end{array}$ & $\mathrm{C}$ & French fry & bread & biscuits & potato chips \\
\hline
\end{tabular}

None had any known developmental delays, based on parent report. Parent informed consent was obtained for all children prior to each child's participation in the study. To fully explain the study to the parents and to reach the maximum consent, an explanatory seminar involving a certified nutritionist was conducted in the school chosen for the study.

\subsection{Study conduction}

The instrument (IBAI) was administered to the 120 Georgian children who underwent a recognition and a recall task. The recall task consisted in the brand naming, in line with the procedure described by Forman et al. [17], and on the product naming. We included also this task (product naming), because sometimes the brand and the name of the product are different from the name of the food itself (e.g., brand: McDonald's ${ }^{\circledR}$; product: Big Mac; food: hamburger). By including also the product naming task, we assumed that this instrument might offer a more reliable measure of children's food brand awareness.

Children were presented with each flash card of the IBAI, one by one. For each flash card children were asked three questions to verify their knowledge about the brands and about the products associated with the selected brands. Pointing at the image of the logo, the experimenter asked, "Do you know the name of this logo?" Once children answered, the experimenter said, "Choose the food that matches with the logo". Finally, when the child selected a food picture, the experimenter asked, "Which is the name of this product?" 


\section{CARD 12}
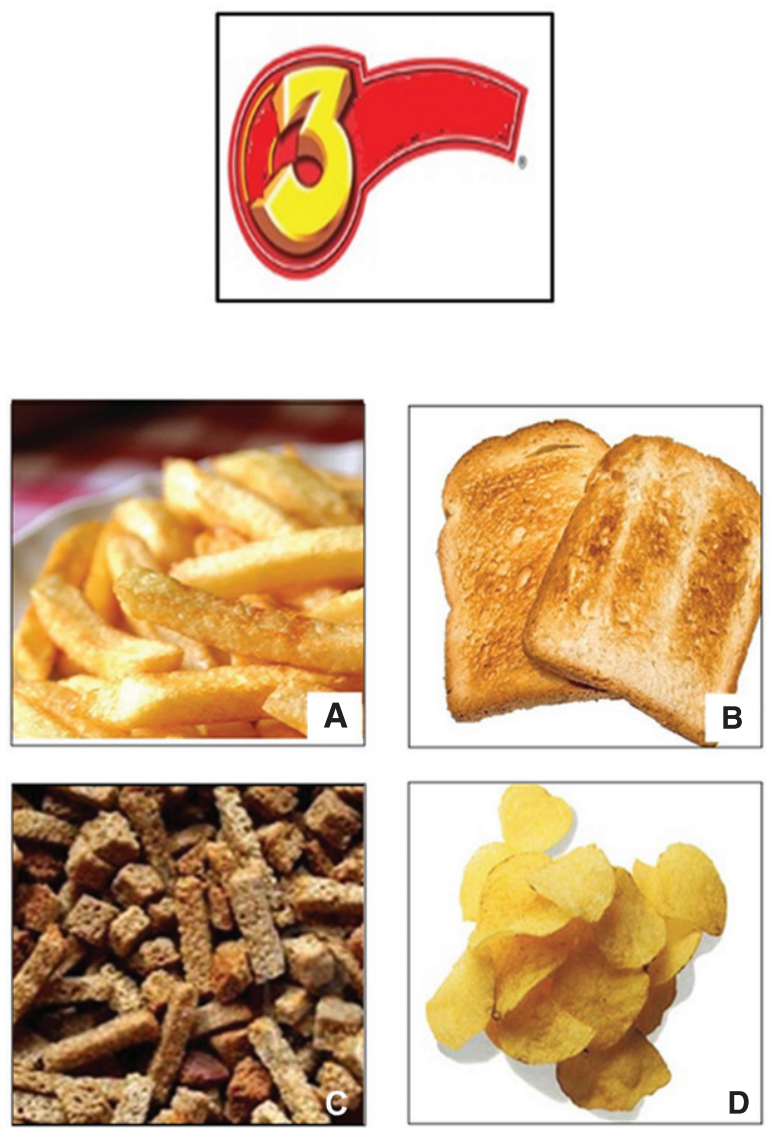

Fig. 1. An example of flash card used in the IBAI Georgia. The logo of 3 Koronchki ${ }^{\circledR}$ (A) was associated with French fries, bread, biscuits and potato chips.

Each card was scored by the experimenter with 1 point if the child correctly named the logo brand, 1 point if the child chose the correct food that matched with the logo, and 1 point if the child correctly named the product. With a total of 12 flash cards, scores on the brand awareness procedure ranged from 0 to 36 (3 points per 12 flash cards) and four different categories of children's brand awareness were identified: 0-12 very low brand awareness; 13-18 medium-low brand awareness; 19-24 medium-high brand awareness; 25-36 very high brand awareness.

The IBAI is freely available for academic and no-profit research at the web address http://www.brand-ibai.com/.

\subsection{Statistical analysis}

Continuous variables were presented as median (I, III quartile). Categorical variables were presented as percentages (absolute numbers) and tested for association with a Chi-Squared test. To analyze the differences in the three tasks of the IBAI (the brand naming, the brand - product association, and the product naming), statistical analysis was performed with Student's $t$ test for paired data. Statistical significance levels used a criterion of $p<0.05$. 
A Rasch model was estimated to assess if the questionnaire presented subsets of tasks with different degrees of difficulty. The model aimed at estimating subjects' probability of correctly answering to each item on the basis of the difficulty of the item (represented by a latent trait included in the model). Goodness of fit of the model was evaluated by calculating the subject's median raw score on two subgroups derived from the original sample and by plotting these estimates and related confidence ellipses.

All analyses have been carried out using the R-System [18].

\section{Results}

Enrolled children's mean age was 6.93 years old $(\mathrm{SD}=2.55)$. Items response distribution (for the correct definition of the brand name, the correct association brand and product, and the correct definition of the product) is presented in Table 2: McDonald $^{\circledR}$ and Bami King ${ }^{\circledR}$ were the brands more often recognized and correctly associated to the corresponding food product.

Table 3 presents total scores stratified by age and gender: children of both gender showed a very low brand awareness (46.7\%), followed by medium-low brand awareness (28.3\%), medium-high brand awareness (19.2\%), and very high brand awareness (5.8\%). Neither female children nor male aged 3-6 belonged to the very high brand awareness group.

Comparing the number of correct responses in the twelve items, the brand-product association task showed a non-significant higher response rate compared to the brand naming task ( $p$-value 0.26) (Fig. 2).

Regarding the results obtained from the estimation of the Rasch model, we found out that not all the tasks had the same probability to be solved out due to different levels of difficulty (Fig. 3). Particularly, the brand naming task had lower probability to be solved compared to other tasks, resulting to be more difficult than the other tasks, especially compared to product naming task which had higher probability to be solved. Additionally, the Rasch model was found to fit well the data: confidence ellipses cross the diagonal, which represented the subject's median raw score calculated on two subgroups derived from the original sample (Fig. 4).

Table 2

Item response distribution for the IBAI

\begin{tabular}{|c|c|c|c|c|c|c|}
\hline \multirow[t]{2}{*}{ Flash card } & \multicolumn{2}{|c|}{ Brand name } & \multicolumn{2}{|c|}{$\begin{array}{l}\text { Brand-product } \\
\text { association }\end{array}$} & \multicolumn{2}{|c|}{ Product name } \\
\hline & $\mathrm{N}$ & $\%$ & $n$ & $\%$ & $n$ & $\%$ \\
\hline 1 & 52 & 43.3 & 53 & 44.2 & 50 & 41.7 \\
\hline 2 & 107 & 89.2 & 106 & 88.3 & 93 & 77.5 \\
\hline 3 & 102 & 85.0 & 105 & 87.5 & 103 & 85.8 \\
\hline 4 & 6 & 5.0 & 44 & 36.7 & 49 & 40.8 \\
\hline 5 & 2 & 1.7 & 31 & 25.8 & 32 & 26.7 \\
\hline 6 & 7 & 5.8 & 31 & 25.8 & 28 & 23.3 \\
\hline 7 & 63 & 52.5 & 57 & 47.5 & 37 & 30.8 \\
\hline 8 & 0 & 0 & 1 & 0.8 & 1 & 0.8 \\
\hline 9 & 3 & 2.5 & 19 & 15.8 & 18 & 15.0 \\
\hline 10 & 3 & 2.5 & 7 & 5.8 & 4 & 3.3 \\
\hline 11 & 66 & 55.0 & 72 & 60.0 & 73 & 60.8 \\
\hline 12 & 47 & 39.2 & 53 & 44.2 & 48 & 40.0 \\
\hline
\end{tabular}


Table 3

Children's total IBAI score stratified by age and gender

\begin{tabular}{|c|c|c|c|c|c|c|c|c|c|c|}
\hline & \multicolumn{4}{|c|}{ Female } & \multicolumn{4}{|c|}{ Male } & \multicolumn{2}{|c|}{ Total } \\
\hline & \multicolumn{2}{|c|}{$3-6$ years } & \multicolumn{2}{|c|}{$7-11$ years } & \multicolumn{2}{|c|}{$3-6$ years } & \multicolumn{2}{|c|}{$7-11$ years } & \multirow[b]{2}{*}{$n$} & \multirow[b]{2}{*}{$\%$} \\
\hline & $n$ & $\%$ & $n$ & $\%$ & $n$ & $\%$ & $n$ & $\%$ & & \\
\hline \multicolumn{11}{|l|}{ IBAI } \\
\hline $0 / 12$ & 18 & $30.0 \%$ & 7 & $11.7 \%$ & 25 & $41.7 \%$ & 6 & $10.0 \%$ & 56 & $46.7 \%$ \\
\hline $13 / 18$ & 11 & $18.3 \%$ & 10 & $16.7 \%$ & 4 & $6.7 \%$ & 9 & $15.0 \%$ & 34 & $28.3 \%$ \\
\hline $19 / 24$ & 1 & $1.7 \%$ & 11 & $18.3 \%$ & 1 & $1.7 \%$ & 10 & $16.7 \%$ & 23 & $19.2 \%$ \\
\hline $25 / 36$ & 0 & $0 \%$ & 2 & $3.3 \%$ & 0 & $0 \%$ & 5 & $8.3 \%$ & 7 & $5.8 \%$ \\
\hline Total & 30 & $50.0 \%$ & 30 & $50.0 \%$ & 30 & $50.0 \%$ & 30 & $50.0 \%$ & 120 & $100.0 \%$ \\
\hline
\end{tabular}

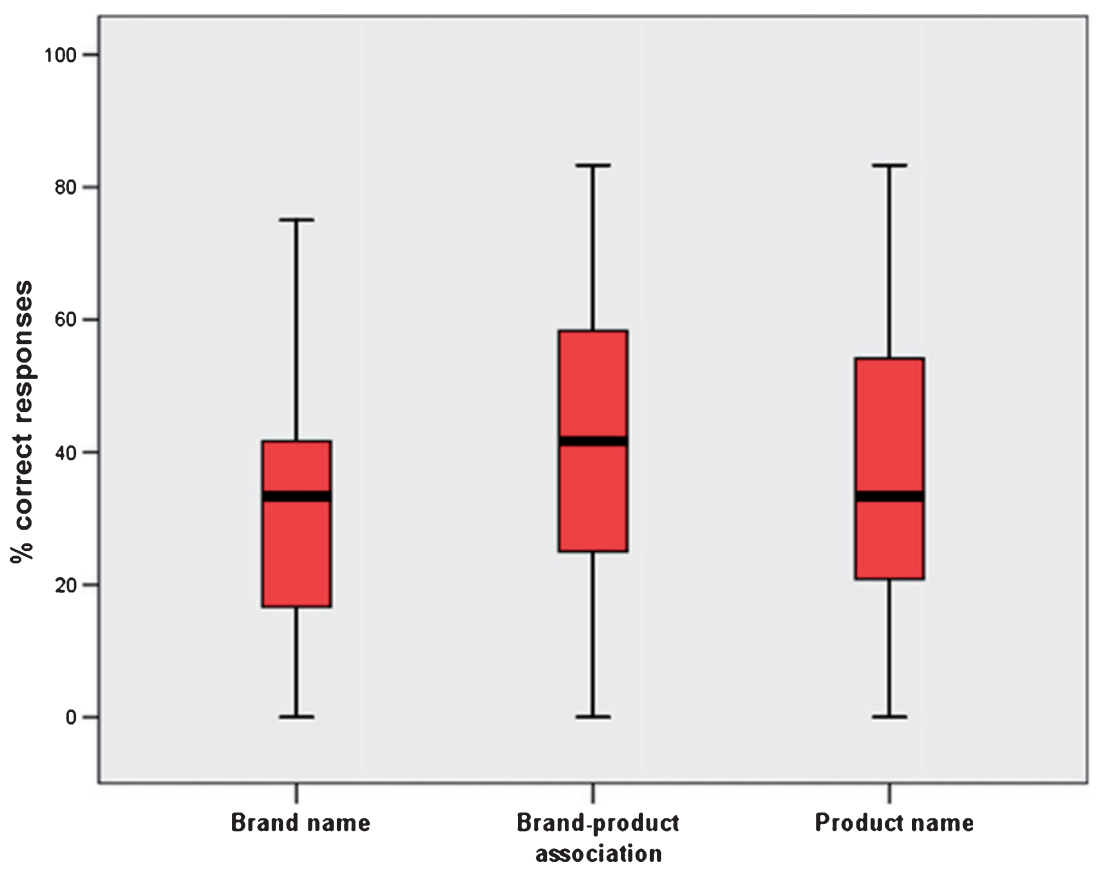

Fig. 2. The number of correct responses for the three tasks of the IBAI.

\section{Discussion}

The rise of childhood obesity represents a severe public health problem worldwide.

The role of food advertising and its relationship with food intake is widely discussed in several studies, showing an association between exposure to food advertising and the consumption of energy-dense, nutrientpoor, food products [19-21]. Our study aimed at evaluating children knowledge and awareness of advertised brands, especially those of sweet and salted snacks and soft drinks, using an instrument estimating children brand awareness. 


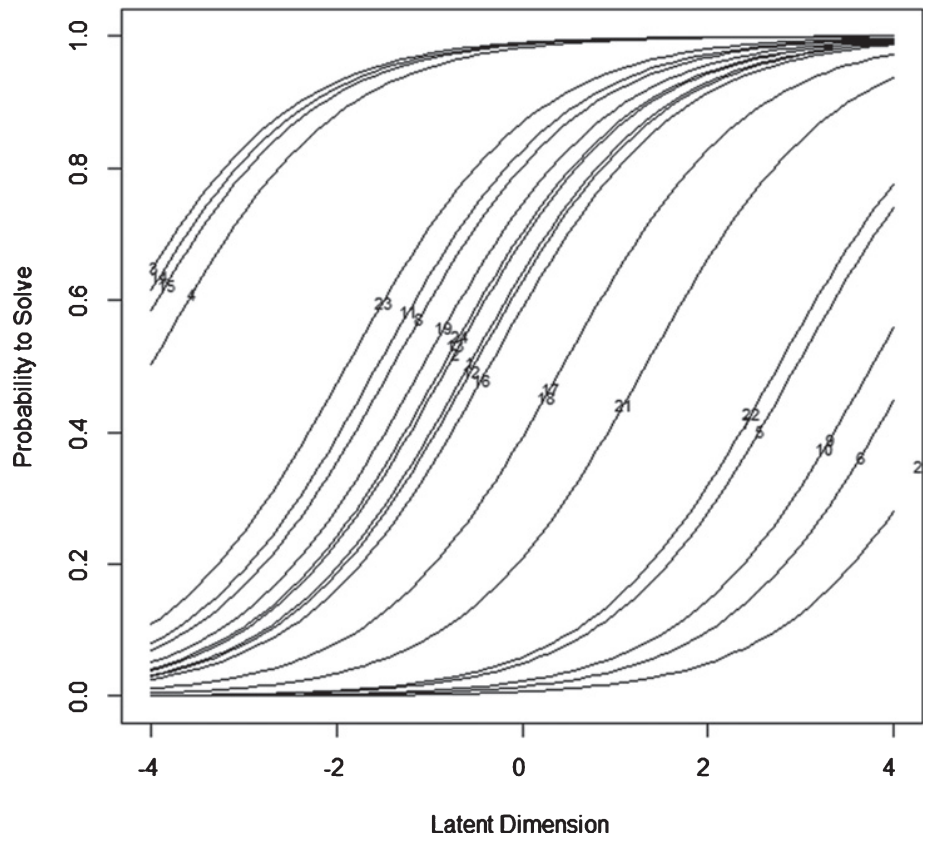

Fig. 3. Item Characteristic Curves.

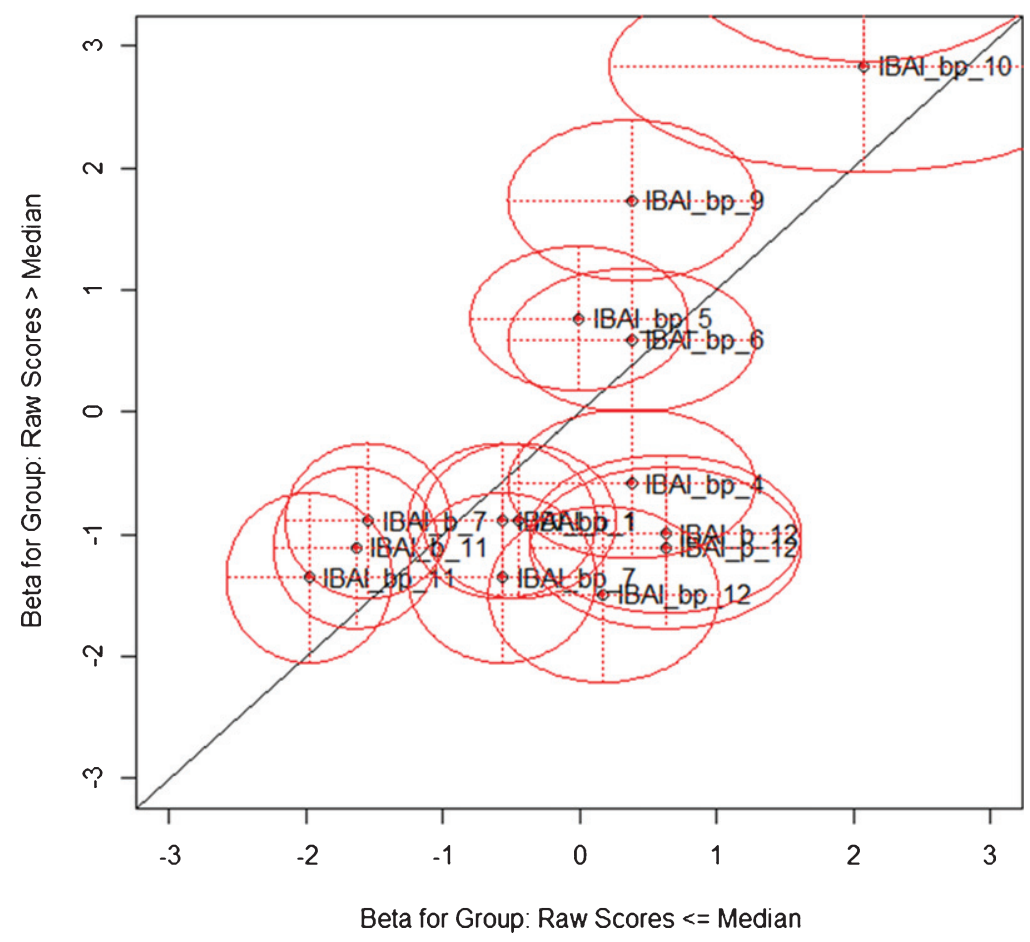

Fig. 4. Graphical check with respect to the median. 
The study showed that the IBAI is an interesting instrument for assessing Georgian children brand awareness. Considering that children IBAI scores ranged in all the four identified categories, we can assume that this instrument allows distinguishing different levels of children's brand awareness.

Furthermore, the results showed that children aged 3-6 demonstrated a very low and medium low brand awareness compared to the older group. This result is in line with Forman et al. [17]: the authors found that the recall exercise was too difficult for some children aged between 4 and 6 years, suggesting that the children age is an important factor in determining their ability to perform in the recall task.

The IBAI is a useful instrument for the analysis of the influence of food marketing on children's diet, considering the increasing rate of childhood overweight. Food advertising might have a detrimental impact on children's food preferences, which, in turn, influence the purchase requests they make to their parents, and, consequently, their dietary patterns. Further studies are necessary to investigate the relationship between children's television exposure and brand-awareness, weight status and food habits, using standardized and validate instruments. In fact, validate instruments specific for each country, such as the IBAI, are very important to study the environmental changes that have facilitated the rapid increase in childhood obesity, and the implication for the marketing of unhealthy foods to children.

\section{Acknowledgments}

Study was supported by an unrestricted grant of Prochild Onlus (www.prochild.eu).

\section{Conflict of interest}

The authors report no conflicts of interest. The authors alone are responsible for the content and writing of the paper.

\section{References}

[1] Lam DW, LeRoith D. The worldwide diabetes epidemic. Current Opinion in Endocrinology, Diabetes, and Obesity. 2012;19(2):93-6.

[2] WHO. Obesity and overweight 2012 May [Available from: http://www.who.int/mediacentre/factsheets/fs311/en/index.html.

[3] Hill JO. Understanding and addressing the epidemic of obesity: An energy balance perspective. Endocrine Reviews. 2006;27:750-61.

[4] Cooper TV, Klesges LM, Debon M, Klesges RC, Shelton ML. An assessment of obese and non obese girls' metabolic rate during television viewing, reading, and resting. Eating Behaviors. 2006;7:105-14.

[5] Campbell KJ, Crawford DA, Ball K. Family food environment and dietary behaviors likely to promote fatness in 5-6 year-old children. International Journal of Obesity. 2006;30:1272-80.

[6] Matheson DM, Killen JD, Wang Y, Varady A, Robinson TN. Children's food consumption during television viewing. American Journal of Clinical Nutrition. 2004;79:1088-94.

[7] Coon KA, Goldberg J, Rogers BL. Relationships between use of television during meals and children's food consumption patterns. Pediatrics. 2001;107:E7.

[8] Halford JC, Gillespie J, Brown V, Pontin EE, Dovey TM. Effect of television advertisements for foods on food consumption in children. Appetite. 2004;42:221-5.

[9] Halford JCG, Boyland MJ, Hughes G, Oliveira LP, Dovey TM. Beyond-brand effect of television (TV) food advertisement/commercials on caloric intake and food choice of 5-7-year-old children. Appetite. 2007;49:263-7.

[10] Epstein LH, Roemmich JN, Robinson JL. A randomized trial of the effects of reducing television viewing and computer use on body mass index in young children. JAMA Pediatrics. 2008;162:239-45.

[11] Harris JL, Pomeranz JL, Lobstein T, Brownell KD. A crisis in the marketplace: How food marketing contributes to childhood obesity and what can be done. Annu Rev Public Health. 2009;30:211-25.

[12] Barr-Anderson DJ, Larson NI, Nelson MC, Neumark-Sztainer D, Story M. Does television viewing predict dietary intake five years later in high school students and young adults? IJBNPA. 2009;6:7. 
[13] Borzekowski DLG, Robinson RN. The 30-second effect: An experiment revealing the impact of television commercials on food preferences of preschoolers. JADA. 2001;101(1):42-6.

[14] Connor SM. Food-related advertising on preschool television: Building brand recognition in young viewers. Pediatrics. 2006;118:147885.

[15] Brody GH, Stoneman Z, Lane TS, Sanders AK. Television food commercials aimed at children, family grocery shopping, and mother-child interactions. Family Relations. 1981;30:435-9.

[16] Robinson TN, Borzekowski DL, Matheson DM, Kraemer HC. Effects of fast food branding on young children's taste preferences. Archives of Pediatrics \& Adolescent Medicine. 2007;161:792-7.

[17] Forman J, Halford JC, Summe H, MacDougall M, Keller K. Food branding influences ad libitum intake differently in children dependingon weight status. Results of a pilot study. Appetite. 2009;53:76-83.

[18] R Core Team. R: A Language and Environment for Statistical Computing. 2012.

[19] Andreyeva T, Kelly IR, Harris JL. Exposure to food advertising on television: Associations with children's fast food and soft drink consumption and obesity. Econ Hum Biol. 2011;9(3):221-33.

[20] Dovey TM, Taylor L, Stow R, Boyland EJ, Halford JC. Responsiveness to healthy television (TV) food advertisements/ commercials is only evident in children under the age of seven with low food neophobia. Appetite. 2011;56:440-6.

[21] Francis LA, Lee Y, Birch LL. Parental weight status and girls' television viewing, snacking, and body mass indexes. Obes Res. 2002;11:143-51. 